\title{
Sobre el cumplimiento de las sentencias del Tribunal de lo Contencioso Administrativo (TCA)
}

\author{
On compliance with the judgments of the Administrative Court
}

\section{Maximiliano Cal Laggiard*}

\footnotetext{
* Magister en Derecho Administrativo Económico (Universidad de Montevideo). Maestrando en Derecho Procesal y aspirante a doctor (Universidad Nacional de Rosario, Argentina). Docente asistente y aspirante a profesor adscripto de Derecho Procesal I y II (Universidad de la República, Uruguay).

$\bowtie$ maximilianomcal@gmail.com
}

RECIBIDO: [15.8.2018]

ACEPTADO: [24.9.2018]

\begin{abstract}
Resumen
Los estudios doctrinarios y los pronunciamientos jurisprudenciales dan muestras de diversas posturas en lo que refiere al modo en que han de cumplirse las sentencias anulatorias del Tribunal de lo Contencioso Administrativo. En el presente trabajo se analizarán los problemas existentes en materia de cumplimiento de sentencias anulatorias del Tribunal de lo Contencioso Administrativo y se valorarán las distintas opciones para el cumplimiento de las referidas sentencias.
\end{abstract}

Palabras clave: derecho administrativo, sentencia judicial, procedimiento legal, teoría legal, Uruguay.

\begin{abstract}
The doctrinal studies and jurisprudential pronouncements show diverse positions concerning the way in which the Administrative Court's annulment judgements should be fulfilled. In the present article, the existing problems regarding compliance with annulment sentences of the Uruguayan Administrative Court will be analyzed and the different options for compliance with the aforementioned judgments will be assessed.
\end{abstract}

Key words: administrative law, legal decisions, legal procedure, legal theory, Uruguay. 


\section{Encuadre}

El 16 de febrero de 2014, el diario El País titulaba en su portada dominical «Fallo histórico», en relación con la sentencia de la Suprema Corte de Justicia 615/2013, de 19 de diciembre de 2013. La referida sentencia, objeto de múltiples comentarios -Martins (2014), Bengoa Villamil (2014) y Cal Laggiard, (2014)—, amparó una pretensión de condena a hacer en contra de una entidad estatal. Como fundamento de la condena, se señaló el cumplimiento de una sentencia anulatoria del TCA.

Tres años más tarde, el semanario Búsqueda, en su edición de 28 de diciembre de 2017, titulaba: «Por primera vez, el TCA asume que tiene competencia para hacer ejecutar sus sentencias y ordena al Estado a acatar un fallo» (Fernández, 2017). La nota periodística refería a la sentencia del TCA 945/2017, de 30 de noviembre de 2017, que ordenó mediante una intimación el cumplimiento de determinadas obligaciones de hacer para la Administración, como consecuencia de una sentencia anulatoria.

Estos dos pronunciamientos jurisdiccionales ponen en evidencia dos enfoques diversos sobre una misma cuestión: cómo se cumplen las sentencias del TCA. Más específicamente, se intenta responder a la pregunta de cuáles son la jurisdicción competente y el procedimiento, en caso de que la Administración no dé cumplimiento voluntario a la sentencia anulatoria del TCA.

Más allá de la inicial divergencia entre las posturas que serán objeto de análisis, ambas parten de un mismo entendimiento, consistente en que las sentencias anulatorias del TCA son pasibles de cumplimiento forzado por vía jurisdiccional, lo cual resulta un postulado esencial en la configuración del Estado de derecho.

\section{Un viejo problema}

Al poco tiempo de la regulación constitucional del proceso contencioso administrativo de anulación, en 1952 (Martins, 2011), se indicó:

[...] la ejecución de la sentencia anulatoria choca con los obstáculos de la propia organización administrativa, con la lentitud de los procedimientos, con dificultades técnicas y, no podemos silenciar, con la mala voluntad de los agentes o gobernantes [...]. (Méndez, 1952, p. 210)

En similar orientación, comentando la regulación constitucional del contencioso administrativo de anulación establecida en la Constitución de 1952, el máximo comentarista de la Carta señaló: 
Es éste, sin duda, uno de los temas más erizados de dificultades de cuantos contiene la Constitución actual [...] Se han introducido en esta Sección enmiendas de importancia. El tiempo que se ha destinado al estudio de esas enmiendas ha sido peligrosamente limitado. Se han abordado cuestiones técnicas de las más difíciles, con extremada rapidez; y el resultado ha sido la sanción de un conjunto de textos de muy confusa interpretación. (Jiménez de Aréchaga, s/f, p. 62)

Pues bien, transcurridos prácticamente 70 años de la regulación constitucional del proceso contencioso administrativo de anulación, aquellos vaticinios primarios fueron plenamente confirmados, de lo cual da cuenta la proliferación de estudios sobre la denominada crisis del proceso contencioso administrativo de anulación, ${ }^{1}$ así como un largo derrotero de proyectos de ley al respecto, e incluso planteos de reforma constitucional. ${ }^{2}$

La problemática observada en el país se ha replicado en el derecho comparado. Así, analizando las dificultades existentes en materia de ejecución de sentencias en el ámbito iberoamericano, se ha señalado:

El capítulo de la ejecución de las sentencias condenatorias de los Entes Públicos pone de manifiesto la quiebra del Estado de Derecho. Cuando los que detentan el Poder no están dispuestos al cumplimiento voluntario de las sentencias, los mecanismos que los Ordenamientos jurídicos arbitran — cuando los arbitran-, por drásticos que sean, se revelan impotentes para lograr que se lleven a puro y debido efecto los pronunciamientos de los fallos contra la voluntad de los obligados. Si, en general, el panorama que nos ofrece el derecho comparado es desalentador, el de los Ordenamientos iberoamericanos alcanza las cuotas más altas de ineficacia. En el de algunos Estados no existe una reglamentación de la ejecución, como reconoce la doctrina más representativa. En el de otros existe una reserva expresa de la competencia ejecutiva a favor de la Administración Pública. En otros, los procedimientos que arbitran son notoriamente insuficientes. Y en los que se llega a una regulación avanzada, la realidad se resiste a su aplicación. (González Pérez, 1995, p. 1380)

También da muestra de las necesidades de reforma, así como de las perspectivas de cambio en la materia, el Proyecto de Código Modelo de Procesos Administrativos -Judicial y Extrajudicial- para Iberoamérica, aprobado el 8 de junio de 2012 en la Asamblea del Instituto Iberoamericano de Derecho Procesal, celebrada en Buenos

1 Véanse Cajarville Peluffo, 2008; Delpiazzo, 2000, 2011; Durán Martínez, 2011, 2015; Labaure, 2010; Prat, 2010; Farinha, 2010; Pereira Campos, 2013; Pezzutti, 2014.

2 Véanse Brito, 2000; Delpiazzo, 2007, 2010, 2016; Cajarville Peluffo, 2016; Klett y Valentín, 2016. 
Aires, que contiene un capítulo con disposiciones expresas en lo que refiere al cumplimiento de sentencias en contra del Estado.

Por su parte, también a nivel de derecho comparado, en la presentación de una obra de análisis de la justicia administrativa en diversos ordenamientos —en su mayoría europeos-, se indicó:

Tampoco se le ocultan al observador los aspectos negativos ni el más grave problema que asola al modelo europeo-continental de justicia administrativa: la dilación de los procesos, la justicia tardía. Ciertamente, la consagración constitucional del derecho a la tutela judicial efectiva, a raíz de la segunda posguerra, trajo como consecuencia una conquista histórica: la proclamación de la universalidad de la jurisdicción que, en su dimensión cuantitativa, proscribe cualquier zona exenta o inmune al enjuiciamiento jurisdiccional. Sin embargo, la otra cara de la medalla, la dimensión temporal de la universalidad de la jurisdicción, la obtención de la tutela judicial en el tiempo adecuado, evitando así la existencia de «lagunas» que, por razón de la excesiva duración del proceso, supongan una denegación efectiva de justicia, sigue siendo todavía una obra inacabada. (Barnés, 1993, pp. 29-30)

Retomando la problemática en el ámbito nacional, entre los principales problemas atinentes al proceso contencioso administrativo de anulación, se han señalado cuestiones relativas a la ejecución de las sentencias, identificando «Dificultades graves para el cumplimiento rápido y efectivo de las sentencias anulatorias del Tribunal (ejecución), que, en los hechos, queda al arbitrio del Estado» (Pereira Campos, 2013, p. 59).

La cuestión atinente a la ejecución de las sentencias del TCA —más concretamente, su deficiente o inexistente ejecución- supone una violación al principio de tutela jurisdiccional efectiva (Durán Martínez, 2014; Ruocco, 2016, Garderes, 2018). Asimismo, tales deficiencias resultan contrarias al derecho humano a la eficiente protección judicial, consagrado por el artículo 25 de la Convención Americana de Derechos Humanos (OEA, 1969).

Respecto al alcance del citado artículo 25 de la Convención, analizando la jurisprudencia de la Corte Interamericana de Derechos Humanos se ha postulado:

[...] no pueden considerarse efectivos aquellos recursos que, por las condiciones generales del país o incluso por las condiciones particulares de un caso dado, resulten ilusorios. Ello puede ocurrir, por ejemplo, cuando su inutilidad haya quedado demostrada por la práctica [...] porque falten los medios para ejecutar sus 
decisiones, o por cualquier otra razón que configure un cuadro de denegación de justicia [...]. (Ibáñez Rivas, 2014, p. 616)

Conforme viene de explicarse, desde la génesis de la regulación constitucional del TCA se han anunciado dificultades relativas a la ejecución de las sentencias de dicho órgano, circunstancia ampliamente confirmada en el transcurso del tiempo.

\section{Alternativas para el cumplimiento de las sentencias}

Ante la falta de cumplimiento voluntario de la sentencia anulatoria por parte de la Administración, en la doctrina se han propuestos diversos medios para la ejecución, que pueden sintetizarse del siguiente modo (Durán Martínez, 2015):

a. intimación de cumplimiento de la sentencia, dispuesta por el TCA a requerimiento del interesado;

b. denuncia penal por omisión contumacial a los deberes del cargo, o desacato a las órdenes jurisdiccionales;

c. denuncia ante los órganos de contralor por el incumplimiento de la sentencia;

d. petición ante la autoridad encargada de ejecutar la sentencia;

e. impugnación en la vía administrativa y jurisdiccional de los actos dictados en contradicción con la cosa juzgada arribada en el TCA;

f. acción reparatoria patrimonial;

g. acción de amparo, e

h. imposición de astreintes. ${ }^{4}$

En términos generales, sobre los diversos medios jurídicos tendientes a la ejecución coactiva de la sentencia anulatoria, resulta categórica la conclusión a la que arriba Martins: «[...] no hay remedio eficaz» (Martins, 1981, p. 69).

Las críticas se orientan en dos direcciones: la escasa utilidad práctica de los medios propuestos (Durán Martínez, 2015) y la actitud asumida por el TCA. En este sentido, Cajarville Peluffo, luego de indicar la grave deficiencia del contencioso administrativo en materia de ejecución de sentencias, sostuvo:

3 En el mismo sentido: Vázquez, 1998; Rotondo Tornaría, 2007; Giorgi, 1958, 1960; Vescovi, 1994; Landoni Sosa, 1977; Goday Cardillo, 2013.

4 En concreto sobre la aplicación de astreintes en el TCA, véase: Durán Martínez, 2007, 2009, Presno, 2010; Duarte y Doldán, 2010; Ruocco, 2016. 
No existe ninguna norma expresa que prevea procedimientos de ejecución de la sentencia anulatoria dictada por el TCA; e invocando con inusitado alcance la disposición constitucional que dispone «se limitará a apreciar el acto en sí mismo, confirmándolo o anulándolo, sin reformarlo» (art. 310), el Tribunal se ha negado siempre a aplicar los procedimientos de ejecución de sentencias previstos en las normas procesales generales. Sólo admite, a petición de parte, practicar intimación de cumplimiento, sin ulteriores consecuencias, y eventualmente dar cuenta a la justicia penal a los efectos pertinentes, que nunca existen. Ninguna de estas medidas, como es comprensible, suele producir efectos satisfactorios para el actor triunfante. (Cajarville Peluffo, 2006, pp. 43-44)

En efecto, la postura del TCA en materia de ejecución de sentencias anulatorias se ha expresado especialmente en las sentencias 38/1986 y 636/1990, donde se consignó:

En materia contencioso-administrativa, por virtud del régimen constitucional vigente - se continuaba en la Sentencia N. ${ }^{\circ}$ 38/986 citada - se ha delimitado con toda precisión las atribuciones del Tribunal que consisten en la motivación de la decisión, y el pronunciamiento expreso de si anula o no anula el acto sometido. Así, el art. 310 de la Constitución (reproducido por el inc. 1..$^{\circ}$ del art. 23 DL N. ${ }^{\circ}$ 15.524) confina [...] a la sola fase de juzgamiento la potestad jurisdiccional, excluyendo la fase de ejecutar lo juzgado [...] 0 sea que se le priva de la potestad de ejecutar y hacer ejecutar la juzgado; lo cual responde a la preocupación que informó todo el proceso de elaboración de las normas constitucionales, de impedir la injerencia del Tribunal en la gestión administrativa o de que en modo o parte alguna pudiere llegar a sustituirse a la Administración. (Considerando II de la sentencia 636/1990) ${ }^{5}$

La postura esgrimida por el TCA, en cuanto a que, según la determinación de competencias constitucionales - artículo 310, inc. 1. ${ }^{\circ}$, de la Carta-, carecería de jurisdicción a efectos de la ejecución de la sentencia anulatoria, ha sido monolíticamente cues-

5 El Tribunal ha seguido la postura sustentada por Vescovi, quien al analizar la Ley Orgánica del TCA, refirió: «Cabe entender, en general, que el Tribunal de lo Contencioso Administrativo, no es un órgano de ejecución de las sentencias que dicta, como los tribunales civiles y penales (o sea todos los demás). Esto se debe fundamentalmente, a la naturaleza especial de las sentencias, y también a una razón de carácter político, derivada de la propia organización del Tribunal, y del régimen de separación de Poderes, que evita conferir facultades administrativas a los órganos jurisdiccionales o poderes de ordenar a la Administración» (Vescovi, 1984, p. 77). 
tionada en doctrina. ${ }^{6}$ En efecto, se ha referido que el TCA es un órgano que ejerce jurisdicción y, citando la definición legal del inciso $1 .^{\circ}$ del artículo $6 .^{\circ}$ de la Ley Orgánica de los Tribunales (ley 15.750, de 24 de junio de 1985), se indica que la jurisdicción supone la «potestad pública de juzgar y hacer ejecutar lo juzgado». Así, se ha dicho:

Esto es frecuente en el ámbito del Tribunal de lo Contencioso Administrativo, cuando el Tribunal, aferrándose a una errónea interpretación restrictiva del artículo 310 de la Constitución, se niega sistemáticamente a aplicar los procedimientos previstos en las normas procesales generales. El artículo 310 citado, en su primer inciso, dice: «El Tribunal se limitará a apreciar el acto en sí mismo, conformándolo o anulándolo, sin reformarlo». El error del Tribunal radica en no haber advertido que esa disposición refiere al contenido de la sentencia definitiva, pero para nada refiere a la ejecución de sentencias. (Durán Martínez, 2016, p. 73)

Cuestionando la indicada postura del TCA, sostuvo Cajarville Peluffo:

[...] lamentablemente, el contenido constitutivo y de condena de la sentencia anulatoria se desdibuja y debilita por la injustificable negativa del TCA a la adopción de medidas coactivas de ejecución de sus sentencias, que cercena a la función jurisdiccional que tiene constitucionalmente atribuida la potestad que le es inherente, además de juzgar, de hacer ejecutar lo juzgado. (Cajarville Peluffo, ${ }^{7}$ 2006, p. 44)

Con relación al respeto de la cosa juzgada anulatoria y, particularmente, a las dificultades para su ejecución coactiva, se impone mencionar el contralor jurisdiccional de los actos administrativos dictados en supuesto cumplimiento de la sentencia anulatoria.

Delpiazzo, 2013; Vázquez, 1998; Rotondo, 2007; Cajarville Peluffo, 2016; Castro Rivera, 1997; Simón, 2012.

7 El citado autor, desentrañando el alcance de la función jurisdiccional constitucionalmente encomendada al TCA, ha postulado que, en el carácter de órgano jurisdiccional del Tribunal, ha asumido competencia para cuestiones diversas al juzgamiento de la legalidad de un acto administrativo, como, por ejemplo, la regulación de honorarios profesionales, y en su mérito ha ordenado la traba de embargos (Cajarville Peluffo, 2016). En efecto, a partir de las sentencias del Tribunal en las que asume competencia y regula honorarios profesionales, se ha sostenido: «Si tal conexión se da entre las causas de acción de nulidad y la regulación de honorarios, por la sola circunstancia de haber ocurrido la segunda en el ámbito procesable de la primera (mismo expediente y órgano, sin siquiera darse los factores de la identidad de las partes y de objeto), parece más que razonable y legítimo al Tribunal adoptar medidas o procesar causas que, conexas con la principal, se encuentren justificadas por ésta y la consecuente necesidad de aseguramiento y cumplimiento. En tal orden pueden citarse, a vía de ejemplo, la adopción de medidas de garantía o cautela, o la ejecución de la sentencia» (Delpiano, 2003, p. 95). 
Estos actos se encuentran sujetos al contralor de legitimidad por el TCA, extremo que, por cuanto supone el agotamiento de la vía administrativa y la deducción de una nueva demanda anulatoria, ha sido calificado como «una burla al derecho» (Méndez, 1952, p. 210) o, tal como refirió Cajarville Peluffo:

Más grave suele ser el «cumplimiento» desviado, la supuesta repristinación de la situación que debiera existir conforme a derecho, con las mismas o con otras ilegitimidades de igual o superior gravedad, que obligan a tramitar nuevas acciones de nulidad contra los actos dictados en sustitución de aquellos anulados; y así puede ocurrir hasta que se agoten las fuerzas o la vida de los lesionados» (Cajarville Peluffo, 2006, p. 44).

Las situaciones que vienen de describirse han sido objeto de tratamiento mediante acciones anulatorias ante el TCA, es decir, se sometieron a conocimiento del Tribunal pretensiones en contra de actos administrativos dictados en aparente contradicción a la cosa juzgada anulatoria.

Los resultados de dichas acciones han sido dispares. Así, la sentencia 807/2006, de 27 de noviembre de 2006, refirió:

[...] resulta inconcuso que el efecto de la sentencia del TCA, determina la necesidad de repristinar la situación a la fecha del acto anulado, restituyendo la situación jurídica vulnerada a la fecha en que ocurrió la lesión. No existe otra opción posible, puesto que, el efecto típico de la sentencia que acoge la pretensión anulatoria, consiste en retrotraer sus efectos, a la fecha del acto anulado. Por ende, dentro de los cometidos funcionales de la Administración, figura la obligación de enmendar un accionar injusto, que derivó del dictado de un acto, atentatorio contra el legítimo derecho del accionante. En síntesis, considera la Sala que no le queda a la Administración otra opción que la de dictar un nuevo acto, que retrotraiga los efectos a la fecha del que fue anulado y disponga en esos términos, el pase a situación de retiro obligatorio del actor.

En similar sentido, la sentencia 623/2012, de 4 de octubre de 2012, dispuso la anulación de la resolución de un gobierno departamental que se apartaba de la cosa juzgada arribada en anterior sentencia del TCA. El pronunciamiento anterior de la corporación había anulado la sanción impuesta en un sumario, considerando como causal de ilegitimidad la desproporcionalidad de la pena y señalando que tales hechos, por los que se imputó falta administrativa, no configuraban una falta grave. La administración demandada, en supuesto cumplimiento del fallo anulatorio, dictó una nueva resolución en el procedimiento disciplinario e impuso una sanción diversa, pero que se 
condecía con las sanciones previstas en los casos de falta grave. El Tribunal, ante el apartamiento del fallo anulatorio mediante el dictado de un acto administrativo que desconocía sus resultancias, dispuso la sanción con costas de la administración.

Por otra parte, las sentencias del TCA 758/2004, de 13 de diciembre de 2004, y $413 / 2013$, de $1 .^{\circ}$ de agosto de 2013 , desestimaron sendas demandas de nulidad, las cuales se fundaban en el incumplimiento de la Administración con sentencias anulatorias; básicamente las sentencias consideraron que los actos administrativos impugnados no se apartaron de la cosa juzgada establecida en anteriores sentencias. ${ }^{8}$

Más recientemente el TCA, mediante la sentencia 945/2017, de 30 de noviembre de 2017, revisó su jurisprudencia en lo que refiere al alcance de su jurisdicción a efectos de la ejecución de sus sentencias. Tras reseñar la relación entre el principio de tutela jurisdiccional efectiva y el cumplimiento de las sentencias, indicó:

[...] la peculiar lectura del art. 310 del texto constitucional, tendiente a evitar la injerencia excesiva del TCA en la gestión administrativa, soslaya que, de principio, toda jurisdicción comprende no solo la potestad para decidir el conflicto sino también la responsabilidad de hacer ejecutar lo juzgado. Como se trata de una solución de principio, su restricción habría requerido un texto constitucional expreso, que no existe. Ordenar y eventualmente constreñir a la Administración a cumplir el fallo anulatorio, no es reformar el acto anulado: es ordenar a quien dictó el acto «ajustarse a las reglas de derecho cuyo incumplimiento motivó la anulación del acto, sin que ello implique incurrir en invasión indebida del fuero administrativo, ya que no se trata de reformar o sustituir el acto por razones de oportunidad o conveniencia». En segundo lugar, las sentencias anulatorias no son sentencias declarativas sino constitutivas y, normalmente, también de condena porque la Administración debe cumplirlas y eso suele exigir que haga o deje de hacer algo.

En la sentencia 758/2004, el Tribunal sostuvo: «En nuestro régimen jurídico, el control de legalidad realizado por el Tribunal no permite sustituir al poder administrador; es por ello que, en la situación planteada, si bien se procedió a anular la designación de la Dra. G. C., esa anulación no presupone la necesaria designación de la impugnante, porque no es posible en nuestro sistema sustituirse las facultades del poder administrador y obligarle a concretar la designación de quien actuó como demandante en la nulidad anterior. La Administración conserva siempre sus facultades discrecionales para actuar y, en el caso, estaba en condiciones de apreciar la necesidad de llenar la vacante o no».

En cuanto a los fundamentos de la solución desestimatoria en la sentencia 413/2013, el Tribunal manifestó: «De lo dicho, se desprende, sin mayor dificultad, que el cumplimiento de la sentencia habrá de tener en cuenta los fundamentos del fallo anulatorio, aunque es indudable que también deberá observar los aspectos jurídicos y fácticos de la nueva realidad, en la cual el nuevo acto habrá de dictarse. Así como la Administración no cumpliría con el fallo si se limitara a reproducir el acto por los mismos motivos ilegítimos que llevaron a su anulación; del mismo modo está obligada a sostener el nuevo acto en circunstancias de hecho o de derecho justificantes de su emisión». 
Asimismo, como se reseñó, también se ha manifestado como alternativa para el cumplimiento de las sentencias anulatorias la promoción de acciones ante el Poder Judicial (Cal Laggiard, 2013, 2018; Cal Laggiard y González Miragaya, 2016). A continuación se analizarán ambas vías propuestas y sus fundamentos.

\section{Jurisdicción del Poder Judicial}

Al postular la jurisdicción del Poder Judicial a efectos de la ejecución de la sentencia anulatoria, a partir del principio consistente en que la función jurisdiccional recae en dicho Poder del Estado, se ha señalado que, si bien las sentencias anulatorias tienen un contenido de condena, dicho contenido no aparece de modo explícito. En consecuencia, el componente de condena debe desentrañarse mediante una pretensión de condena a hacer, dar o no hacer, que se sustanciará bajo la ritualidad del proceso ordinario, por cuanto no existe una vía procesal específica para el tratamiento de dichas pretensiones.

En lo que refiere a la naturaleza jurídica de la sentencia anulatoria, se ha indicado:

La sentencia anulatoria tiene una naturaleza múltiple: es declarativa en tanto pone de manifiesto que el acto viola una regla de derecho y, por ello, lo anula; es - a la vez - constitutiva, porque determina la inexistencia jurídica de aquél, su extinción retroactiva, y también implica una condena a la Administración autora del acto, ya que debe hacer o no hacer todo lo necesario para la ejecución de la sentencia, partiendo de la base de la referida inexistencia. ${ }^{9}$ (Rotondo, 2007: 84; Vázquez, 1998; Ruocco, 2016)

En cuanto al contenido de condena que se atribuye a la sentencia anulatoria, se ha sostenido: 
Dado la índole de esta jurisdicción el fallo invalida el acto, le priva de todos sus efectos jurídicos. La ejecución, pues, es una consecuencia natural, directa e inmediata del pronunciamiento jurisdiccional. No se necesitaría, por consiguiente, una decisión declarativa del órgano demandado, que sería redundante. Pero hay que separar el efecto directo del fallo anulatorio sobre el acto objeto de la litis, de los efectos mediatos, de las consecuencias que trae la anulación misma incidiendo sobre otras situaciones. (Méndez, 1952, p. 209)

La distinción realizada por Méndez entre efectos inmediatos —efecto constitutivo del fallo anulatorio- y efectos mediatos resulta enteramente compartible. Entre los efectos mediatos pueden ubicarse los referidos precedentemente en cuanto al sentido ordinario de ejecución de sentencia como cumplimiento de esta. Al respecto, con toda precisión, decía Real:

[...] la ejecución, leal y completa, de la sentencia anulatoria envuelve también un aspecto positivo imprescindible para satisfacer a la vez el interés y el derecho del actor triunfante y realizar la recompensación del orden jurídico vulnerado; esto es que la ejecución impone deberes positivos; obliga a hacer con arreglo a derecho lo que antes se hizo con violación de la regla de derecho, a hacer bien lo que antes se hizo mal. (Real, 1970, pp. 349-350)

Las consecuencias intrínsecas a la anulación suponen evidentemente un contenido de condena. No obstante, tal como lo apreció Méndez, el citado contenido es mediato (Cal Laggiard y González Miragaya, 2016), extremo que, sumado a la ausencia de regulación específica en materia de ejecución forzada de sentencias anulatorias, explica las dificultades para la realización jurisdiccional - ejecución forzada- del contenido de condena. En efecto, importa recordar que solo las sentencias de condena son pasibles de ejecución forzada (Couture, 2004).

A partir de las consideraciones precedentes, se ha postulado que la vía para explicitar el contenido de condena implícito en la sentencia anulatoria está dada por el proceso ordinario ante el Poder Judicial, a efectos de delimitar una obligación concreta de la Administración como consecuencia de la sentencia anulatoria del TCA (Cal Laggiard, 2013, 2018; González Miragaya y Cal Laggiard, 2016). Al respecto, existe consenso en la doctrina sobre la admisibilidad y la fundabilidad de acciones declarativas y de condena, tendientes a la imposición de un hacer concreto en contra de una entidad estatal (así: Cassinelli Muñoz, 1971; Cajarville Peluffo, 1989; Castro Rivera, 2000; Delpiazzo, 2013).

En el ámbito iberoamericano, en las XXIII Jornadas Iberoamericanas de Derecho Procesal (Buenos Aires en 2012) se presentó el Proyecto de Código Modelo de Procesos 
Administrativos -Judicial y Extrajudicial- para Iberoamérica (IIDP, 2012), que contiene expresas disposiciones respecto a las pretensiones admisibles en contra de la Administración (artículo 24), sobre el contenido de condena de tales sentencias (artículo $55)^{10}$ y disposiciones específicas en materia de ejecución (artículos 62 y siguientes).

Por lo tanto, la posición que viene de reseñarse determina, a partir del contenido de la sentencia del TCA, la viabilidad de promover un proceso ordinario ante el Poder Judicial con la finalidad de obtener una condena concreta, que podrá acumularse, de modo conjunto o subsidiario, con la acción reparatoria patrimonial (Cal Laggiard, 2014, 2018).

\section{Jurisdicción del TCA}

Según viene de adelantarse, a diferencia de la postura precedente, se ha indicado que el único modo de cumplimiento de las sentencias del TCA está dado por la jurisdicción del Tribunal, particularmente a través de la imposición de astreintes (Garderes, 2018).

Al respecto, la indicada sentencia del TCA 945/2017 reseñó expresamente la vinculación entre el principio de tutela jurisdiccional efectiva y el cumplimiento de las sentencias, al señalar:

Asistimos a una cuestión reiteradamente planteada por la doctrina y que se relaciona con el ideal de tutela jurisdiccional efectiva que es inherente a la idea de un Estado de Derecho. De poco sirven los derechos si no hay modo de hacerlos efectivos y por eso la exigencia de acceso a la justicia y de que existan medios de hacer cumplir las decisiones jurisdiccionales. Y esa protección efectiva de los derechos de ningún modo excluye aquellos que se puedan tener contra el Estado.

A partir de lo anterior, a efectos de fundar el alcance de la jurisdicción del Tribunal, luego de reseñar que el artículo 310 de la Carta no obsta a la ejecución de las sentencias, se señaló que normalmente las sentencias anulatorias suponen un contenido de condena. En consecuencia, se refirió que el Tribunal se encuentra habilitado a emitir una orden de cumplimiento de la sentencia, en la cual, además de la intimación,

«Art. 55. (Contenido de la sentencia) La sentencia podrá tener naturaleza declarativa, constitutiva o condenatoria, incluyendo obligaciones de dar, hacer o no hacer, pudiendo el órgano jurisdiccional, para restablecer el derecho particular, fijar disposiciones nuevas en lugar de las impugnadas y modificarlas o reformarlas. La sentencia debe pronunciarse sobre los daños y perjuicios que hayan sido reclamados». 
conste el itinerario completo de lo que deberá hacer la Administración a efectos de dar cumplimiento a la sentencia anulatoria. Así, la referida sentencia postuló:

La decisión del Tribunal se ajusta también a una práctica exitosa de la justicia contencioso administrativa francesa - pionera en la materia- que consiste en aconsejar a quien debe cumplir una decisión adoptada sobre la ejecución correcta de esa decisión. La llamada «injonction» es una orden precisa y no discutible, que debe ser obligatoriamente ejecutada en cierto plazo y que, con frecuencia, es acompañada de una amenaza de sanción como son las «astreintes». (García de Enterría, 1999)

Continuando con el análisis de la sentencia en cuestión, importa señalar que la innovación radicó en que la sentencia dispuso concretamente la conducta esperada por la Administración como consecuencia del fallo anulatorio e intimó su cumplimiento. No obstante, si bien parece entreverse la eventualidad de la aplicación de astreintes por el Tribunal, dicha medida no fue dispuesta en la sentencia, por lo cual permanece la incógnita en lo que refiere a la adopción de conminaciones económicas por parte del TCA.

Al respecto, la indicada sentencia 945/2017 contó con una extensa discordia del ministro Echeveste. Esta no refiere a una solución distinta de aquella a la que arribaron los restantes ministros, sino que es una resolución coincidente, en la cual, a los efectos de reforzar la argumentación y expresar la diversidad de fundamentos para llegar a una misma decisión, consta el voto del ministro (así: artículo 91, inciso 2. ${ }^{\circ}$, del decreto ley 15.524, de 9 de enero de 1984). El señalado voto discorde insiste en lo referente a la ejecución de la sentencia, así como a la eventualidad de la aplicación de astreintes, en similar sentido a la discordia de dicho ministro extendida en la sentencia del TCA 329/2017, de 16 de mayo de 2017.

\section{Valoración final}

Ambas posiciones, según lo indicado, parten de la necesidad de cumplimiento pleno de las sentencias anulatorias del TCA, como corolario del principio de tutela jurisdiccional efectiva.

Sin embargo, resulta precipitado, a priori, postular que una posición excluye a la otra, es decir, sostener una jurisdicción exclusiva y excluyente por parte del TCA.

En tal sentido, la antedicha postura y, consecuentemente, la posición negadora de la jurisdicción del Poder Judicial, con el alcance que viene de especificarse, resultaría incluso contraria al anunciado principio de tutela jurisdiccional efectiva. 
Así, en sede de ejecución de sentencia, aun en el TCA necesariamente debe configurarse una etapa de conocimiento, a efectos de desentrañar el alcance de condena de la sentencia anulatoria y explicitarlo.

Sobre el punto —-salvando las distancias, dada la existencia de expresa normativa constitucional al respecto- cabe hacer un parangón con la acción reparatoria patrimonial por actos administrativos ilícitos anulados por el TCA, en la cual la vía para reclamar la reparación está dada por el proceso ordinario.

Al respecto, se ha señalado:

La sentencia anulatoria del Tribunal declara en forma definitiva la invalidez del acto, cuestión esta que no puede ser discutida nuevamente ante el Poder Judicial. Pero para obtener la reparación patrimonial ante los tribunales ordinarios, el accionante debe probar la existencia del daño, su cuantía y el nexo causal con el acto anulatorio. Esto es lógico porque no todos los actos irregulares originan perjuicios, ni todo perjuicio es indemnizable. El procedimiento a seguir en la reclamación patrimonial es el juicio ordinario. La acción no puede encararse como una liquidación de perjuicios en ejecución de la sentencia anulatoria, porque es preciso demostrar la relación causal entre el acto y el daño. Lo que está fuera de litigio es la invalidez del acto como fuente del derecho a indemnización. (Sayagués Laso, 2010: 565)

En efecto, los daños causados por un acto administrativo ilícito, anulado por el TCA, requieren para su acreditación de un proceso ordinario. Ahora bien, el mismo razonamiento resulta de aplicación al modo en que la Administración debe cumplir la sentencia anulatoria.

Por otra parte, el proceso ordinario no resulta contrario a los lineamientos del principio de tutela jurisdiccional efectiva; más aún, como máxima estructura procesal, reporta las mayores garantías para todas las partes.

Así, a simple vía de ejemplo, vale preguntarse qué pasaría si el TCA indicara la inadmisibilidad de la ejecución de la sentencia. En tal sentido, tratándose de un órgano de instancia única, la decisión no resultaría revisable, circunstancia que sí acontece en el Poder Judicial e informa al contenido del principio de tutela jurisdiccional.

En la misma orientación, en lo que refiere a la celeridad del proceso, aun de modo previo al proceso ordinario, es posible la adopción de medidas provisionales a efectos de garantizar el cumplimiento de las sentencias anulatorias.

Al respecto, cabe sostener que, en materia de ejecución de sentencias anulatorias, la competencia originaria para la ejecución radica en el TCA. Sin embargo, ante la falta de medios legislativos específicos para la ejecución, resulta plausible y acorde con los lineamientos emanados del principio de tutela jurisdiccional efectiva la promoción de 
acciones de cumplimiento de la sentencia anulatoria ante el Poder Judicial, a efectos de desentrañar el contenido de condena, ínsito en el pronunciamiento anulatorio.

\section{Bibliografía}

BARNÉS, J. (1993). La justicia administrativa en el derecho comparado. Madrid: Civitas. BEnGOA Villamil, R. (2014). «Nulidad absoluta insubsanable: Casos de incompetencia absoluta (falta de jurisdicción) y de indefensión procesal». La Justicia Uruguaya, $149,123-134$.

BRITo, M. R. (2000). «De la justicia de lo contencioso administrativo». Anuario de Derecho Administrativo, 8, 80-90.

Cajarville Peluffo, J. P. (1989). «Contencioso administrativo de reparación patrimonial». Revista Uruguaya de Derecho Procesal, 1, 16-28.

Cajarville Peluffo, J. P. (2006). «Visión actual del contencioso administrativo uruguayo». Judicatura, 44, 35-53.

Cajarville Peluffo, J. P. (2008). Sobre Derecho Administrativo: Tomo II (2. ${ }^{\text {a }}$ ed.). Montevideo: FCU.

Cajarville Peluffo, J. P. (2016). «Una debilidad del sistema: La ejecución de la sentencia en el Tribunal de lo Contencioso Administrativo». Revista de Derecho Público, 25(49), 149-159.

CaL LagGiard, M. (2013). «Cuestiones procesales del cumplimiento de la sentencia anulatoria del TCA». Revista Uruguaya de Derecho Procesal, 2, 209-225.

CAL LAGGiARD, M. (2014). «Contencioso administrativo de reparación patrimonial». Revista de la Facultad de Derecho, 37, 79-110.

CAL LAgGiard, M. (2014). «Suprema Corte de Justicia: Sobre el cumplimiento de las sentencias anulatorias del TCA». Tribuna del Abogado, 187, 19-22.

Cal Laggiard, M. (2018). Efectos de las sentencias del Tribunal de lo Contencioso Administrativo. Montevideo: La Ley Uruguay.

CAl Laggiard, M. \& GonzÁlez Miragaya, S. (2016). «Sentencia anulatoria del TCA: Su acatamiento por la Administración y la pretensión de recomposición del ganancioso». En Estudios sobre la Administración uruguaya: Tomo II (pp. 261-267). Montevideo: FCU.

CASSINELli MuÑOZ, H. (1971). «Acción de reparación y extinción del acto dañoso en vía administrativa». Revista de Derecho, Jurisprudencia y Administración, 71, 74-75.

CAStro Rivera, A. (1997). «Ejecución de sentencias contra personas públicas estatales». En IX Jornadas Nacionales de Derecho Procesal (pp. 59-79). Montevideo: UdelaR.

CASTRo Rivera, A. (2000). «Pretensiones contra personas estatales y justicia ordinaria». Revista de Derecho Público, 17, 47-58. 
Couture, E. (2004). Fundamentos del derecho procesal civil (4. ${ }^{\mathrm{a}}$ ed.). Buenos Aires: $\mathrm{B}$ de F.

Delpiano, H. (2003). «Acerca de la competencia no originaria del Tribunal de lo Contencioso Administrativo». Anuario de Derecho Administrativo, 10, 93-96.

DELPIAZzo, C. (2000). «Apuntes para una revisión del contencioso administrativo uruguayo». Revista de la Facultad de Derecho y Ciencias Sociales, 17, 51-59.

DELPIAZZo, C. E. (2007). «Imprescindible reorganización de lo contencioso administrativo». Revista de Derecho de la Universidad de Montevideo, 4(12), 123-128.

DELPIAZZO, C. E. (2010). «Nuevamente sobre las soluciones posibles a los problemas organizativos del contencioso anulatorio». Revista de Derecho de la Universidad de Montevideo, 9(18), 89-97.

DELPIAZzo, C. E. (2011). «Diez problemas relativos a la tutela jurisdiccional efectiva en el contencioso administrativo uruguayo». AIDA. Revista de la Asociación Internacional de Derecho Administrativo, 5(9), 71-96.

DELPIAZZo, C. E. (2013). Derecho administrativo general: Volumen II. Montevideo: AMF.

DELPIAZZO, C. E. (2016). «Reforma del contencioso administrativo de anulación». En Estudios sobre la Administración Uruguaya: Tomo II (pp. 419-430). Montevideo: FCU.

DuARTE, M. \& Doldan, S. (2010). «El TCA puede y debe ejecutar sus sentencias». Revista CADE - Doctrina y Jurisprudencia, 2(5), 47-55.

DurÁn MARTíneZ, A. (2007). «Ejecución de la sentencia anulatoria en el contencioso administrativo uruguayo». La Justicia Uruguaya, 136, 141-148.

DURÁn MARTínEZ, A. (2009). "Algunas cuestiones relativas a la responsabilidad del Estado por incumplimiento de sentencias». Estudios Jurídicos, 6, 61-89.

DuRÁn MARTíneZ, A. (2011). «Debilidades actuales del contencioso anulatorio». La Justicia Uruguaya, 144, 171-176.

DuRÁn MARTínEZ, A. (2014). «La tutela jurisdiccional efectiva y el contencioso administrativo de anulación en Uruguay». Estudios Jurídicos, 13, 115-157.

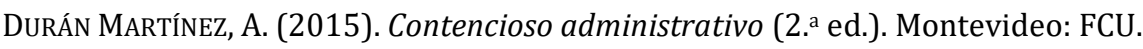

DURÁN MARTínEZ, A. (2016). «La jurisdicción contenciosa-administrativa en el estado democrático de derecho: La posición jurídica del ciudadano». En Estudios de Derecho Administrativo, 14, 73-111.

FARINHA, F. (2010). «Problemas del contencioso anulatorio II». En C. E. DELPIAZzo (coord.), Transformaciones actuales del Derecho Administrativo (pp. 369-383). Montevideo: FCU.

FERNÁNDEZ, V. (28 de diciembre, 2017). «Por primera vez, el TCA asume que tiene competencia para hacer ejecutar sus sentencias y ordena al Estado a acatar un fallo». Seminario Búsqueda, 1950. Recuperado de https://www.busqueda.com.uy/nota/ 
por-primera-vez-el-tca-asume-que-tiene-competencia-para-hacer-cumplir-sussentencias-y-ordena.

GARCÍA DE ENTERRÍA, E. (1999). «Contencioso-administrativo objetivo y contenciosoadministrativo subjetivo a finales del siglo XX: Una visión histórica y comparatista». En Colloque du deuxiénie centenaire du Conseil d'état, París.

GARDERES, S. (2018). «Medidas para la efectividad de la sentencia anulatoria de actos administrativos». Revista Uruguaya de Derecho Procesal - Procesos Constitucionales, 865-887.

GIORGI, H. (1958). El contencioso administrativo de anulación. Montevideo: Facultad de Derecho y Ciencias Sociales (UdelaR).

GIORGI, H. (1960). «Cumplimientos de los fallos por la Administración». La Justicia Uruguaya, 60, $13-22$.

GodAY CARDillo, K. (2013). "Análisis de la sentencia del TCA N. ${ }^{\circ}$ 246/2009 en lo relativo a las dificultades en la etapa de ejecución de sentencias anulatorias». Revista de Derecho de la Universidad de Montevideo, 12(23), 65-76.

GonZÁlEz PÉREZ, J. (1995). «Panorama de la justicia administrativa en los ordenamientos hispanoamericanos». En Homenaje a José María Chico y Ortiz (pp. 1367 1381). Madrid: Marcial Pons.

IBÁÑEz Rivas, J. M. (2014). «Artículo 25 - Protección judicial». En C. STEInER y P. URiBE (eds.), Convención Americana sobre Derechos Humanos: Comentario (pp.606653). Berlín: Fundación Konrad Adenauer.

IIDP (2012). Proyecto de Código Modelo de Procesos Administrativos. Recuperado de http://www.iibdp.org/es/documentos/139-proyecto-de-codigo-modelo-deprocesos-administrativos.html.

JimÉNEz De ArÉchaGA, J. (s.f.). La Constitución del Uruguay de 1952: Volumen 1. Montevideo: Centro Estudiantes de Derecho.

KLETT, S. \& G. VALENTín (2016). «La reforma del proceso contencioso administrativo de anulación». Estudios sobre la Administración Uruguaya: Tomo II (pp. 369-391). Montevideo: FCU.

LABAURE, C. (2010). «Tipos de control jurisdiccional de la administración y sus insuficiencias». En C. DElPIAzzo (coord.), Transformaciones actuales del Derecho Administrativo (pp. 347-357). Montevideo: FCU.

LANDONi SoSA, A. (1977). El proceso contencioso administrativo de anulación. Montevideo: Acali.

Ley 15.750 (1985). Ley Orgánica de la Judicatura y de Organización de los Tribunales. Recuperado de https://parlamento.gub.uy/documentosyleyes/leyes/ley/15750? width $=800 \&$ height $=600 \&$ hl=en_US1\&iframe=true \&rel=nofollow. 
MARTINS, D. H. (1981). «Acciones procesales administrativas de plena jurisdicción y de anulación». En Justicia Administrativa (pp. 51-70). Tucumán: Universidad del Norte Santo Tomás de Aquino.

MARTins, D. H. (2011). «Historia de la creación en 1952 del Tribunal de lo Contencioso Administrativo y de las modificaciones posteriores». La Justicia Uruguaya, 144, 91-102.

MARTins, D. H. (2014). «Ejecución por el Poder Judicial de sentencia del TCA que anula un acto administrativo de permiso de construcción: Demolición de edificio construido con permiso ilícito. El caso Edificio Balleneros (Punta del Este)». La Justicia Uruguaya, 149, 73-93.

MÉndeZ, A. (1952). Lo contencioso de anulación en el derecho uruguayo. Montevideo: Biblioteca de la Revista de Derecho Público y Privado.

OEA (1969). Convención Americana sobre Derechos Humanos (Pacto de San José). Recuperado de https://www.oas.org/dil/esp/tratados_B-32_Convencion_ Americana_sobre_Derechos_Humanos.pdf.

PEREIRA CAMPOS, S. (2013). «Crisis del proceso contencioso administrativo de anulación: algunas propuestas para su reforma». En XVI Jornadas Nacionales de Derecho Procesal (pp. 57-69). Montevideo: Mastergraf.

Pezzutti, M. (2014). «Perspectivas del contencioso anulatorio (con especial énfasis en el acceso)». En Jornadas en homenaje al Prof. Dr. Mariano R. Brito (pp. 191-226). Montevideo: Universidad de Montevideo.

Prat, A. (2010). «Problemas del Contencioso Anulatorio I». En C. E. DELPIAZzo (coord.), Transformaciones actuales del Derecho Administrativo (pp.359-368). Montevideo: FCU.

Presno, M. (2010). «Aplicación de instrumentos comunes del Derecho Procesal para la ejecución de Sentencias. Astreintes». En IV Jornadas Académicas del Tribunal de lo Contencioso Administrativo en homenaje al Prof. Dr. Mariano Brito (pp. 91113). Montevideo: FCU.

REAL, A. R. (1970). «Ejecución de sentencia anulatoria: Derecho al ascenso en los entes autónomos». Revista de la Facultad de Derecho y Ciencias Sociales, 21(1-4), 347-362.

Rotondo Tornaría, F. (2007). «Sentencias anulatorias del Tribunal de lo Contencioso Administrativo: Su cumplimiento». Transformación, Estado y Democracia - Publicación de la Oficina Nacional de Servicio Civil, 2(33), 83-91.

Ruocco, G. (2016). «Proyección del principio de la tutela judicial efectiva sobre la ejecución de la sentencia estimatoria en el proceso de anulación de actos administrativos». Estudios de Derecho Administrativo, 14, 427-461.

Sayagués Laso, E. (2010). Tratado de Derecho Administrativo: Tomo II (8. a ed.). Montevideo: FCU. 
SimóN, L. M. (2012). «XVI Jornadas Nacionales de Derecho Procesal. Relato de las ponencias presentadas. Tema I: Proceso contencioso administrativo de anulación y reparación». Revista Uruguaya de Derecho Procesal, 2, 1119-1124.

VÁZquEZ, C. (1998). «Ejecución de la sentencia anulatoria». En Responsabilidad del Estado y jurisdicción (pp. 51-66). Trabajo presentado al 4. ${ }^{\circ}$ Coloquio - Contencioso de Derecho Público, Montevideo, Uruguay.

VESCOVI, E. (1984). «Los procesos contenciosos administrativos». En El nuevo régimen judicial: Primera lectura de la nueva ley de lo contencioso administrativo y el régimen de competencia y de turnos vigentes a partir del 1. ${ }^{\circ}$ de enero de 1984 (pp. 4983). Montevideo: Idea.

VesCovi, E. (1994). «El proceso contencioso administrativo». La Justicia Uruguaya, $88,5-20$.

\section{Jurisprudencia}

Uruguay. Tribunal de lo Contencioso Administrativo. Sentencia 758/2004. (13/12/2004). Mercant, M. (redactor); Baldi, J.; Brito del Pino, E.; Rochón, C.; Battistella, M. (firmantes).

Uruguay. Tribunal de lo Contencioso Administrativo. Sentencia 807/2006. (27/11/2006). Preza, D. (redactor); Rochón, C.; Battistella, M.; Lombardi, E.; Harriague, R.; Petraglia, M. C. (firmantes).

Uruguay. Tribunal de lo Contencioso Administrativo. Sentencia 623/2012. (04/10/2012). Sassón, M. (redactor); Preza, D.; Harriague, R.; Gómez Tedeschi, A.; Tobía, J. P.; Marquisio, R. (firmantes).

Uruguay. Tribunal de lo Contencioso Administrativo. Sentencia 413/2013. (01/08/2013). Harriague, R. (redactor); Gómez Tedeschi, A.; Preza, D.; Sassón, M.; Tobía, J. P.; Gianarelli, S. (firmantes).

Uruguay. Tribunal de lo Contencioso Administrativo. Sentencia 329/2017. (16/05/2017). Castro, A. (redactor); Gómez Tedeschi, A.; Vázquez Cruz, E.; Echeveste, J. (discordante).

Uruguay. Tribunal de lo Contencioso Administrativo. Sentencia 945/2017. (30/11/2017). Castro, A. (redactor); Gómez Tedeschi, A.; Tobía, J. P.; Vázquez Cruz, E.; Echeveste, J. (discordante). 